\title{
Apoptosis-inducing factor deficiency decreases the proliferation rate and protects the subventricular zone against ionizing radiation
}

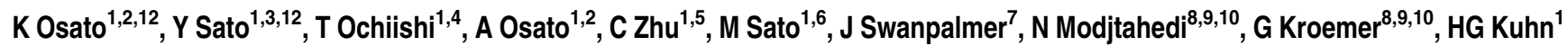 \\ and K Blomgren ${ }^{*, 1,11}$
}

Cranial radiotherapy in children often leads to progressive cognitive decline. We have established a rodent model of irradiationinduced injury to the young brain. A single dose of $8 \mathrm{~Gy}$ was administered to the left hemisphere of postnatal day 10 (P10) mice. Harlequin $(\mathrm{Hq})$ mice, carrying the hypomorphic apoptosis-inducing factor $\mathrm{AlF}^{\mathrm{Hq}}$ mutation, express $60 \%$ less AIF at P10 and displayed significantly fewer dying cells in the subventricular zone (SVZ) $6 \mathrm{~h}$ after IR, compared with wild type (Wt) littermates. Irradiated cyclophilin A-deficient $\left(\mathrm{CypA}^{-I-}\right)$ mice confirmed that CypA has an essential role in AIF-induced apoptosis after IR. $\mathrm{Hq}$ mice displayed no reduction in SVZ size 7 days after IR, whereas $48 \%$ of the SVZ was lost in Wt mice. The proliferation rate was lower in the SVZ of Hq mice. Cultured neural precursor cells from the SVZ of Hq mice displayed a slower proliferation rate and were more resistant to IR. IR preferentially kills proliferating cells, and the slower proliferation rate in the SVZ of Hq mice may, at least partly, explain the protective effect of the Hq mutation. Together, these results indicate that targeting AlF may provide a fruitful strategy for protection of normal brain tissue against the detrimental side effects of IR.

Cell Death and Disease (2010) 1, e84; doi:10.1038/cddis.2010.63; published online 21 October 2010

Subject Category: Neuroscience

Approximately one-third of all childhood cancers are brain tumors. ${ }^{1}$ About $70 \%$ of pediatric brain tumor patients survive, and the survival rate has improved dramatically over the last 20 years. $^{2,3}$ Radiotherapy (RT) is one of the most effective treatments for malignant brain tumors. ${ }^{4}$ Cognitive deficits are some of the most common and serious long-term complications, so called late effects, of $\mathrm{RT}^{4-6}$ These symptoms were most severe in children treated with RT at the age of 3 years or younger. ${ }^{7-10}$ Even low doses of ionizing radiation to the CNS may cause cognitive impairment ${ }^{11}$ and the cognitive deficits observed after RT increase over time. ${ }^{12,13}$ Ameliorating the late effects caused by RT would greatly improve the quality of life of the increasing number of childhood cancer survivors. However, no effective methods for protecting the normal brain tissue have been established and there is a lack of animal models investigating strategies to limit the debilitating effects of cranial RT. ${ }^{14-19}$

Neurogenesis occurs throughout life in the subventricular zone (SVZ) and the subgranular zone of the dentate gyrus, ${ }^{20-22}$ making them particularly susceptible to IR-induced apoptosis. ${ }^{14,15,23,24}$ Therapeutic doses of irradiation (IR) result in increased apoptosis, ${ }^{23,25}$ decreased cell proliferation and reduced stem/progenitor cell differentiation into neurons within the neurogenic regions, both in rodents ${ }^{24,26}$ and in humans. ${ }^{27}$ There are two distinct pathways leading to nuclear apoptosis, caspase-dependent and caspaseindependent. $^{28-30}$ One of the key components of the caspase-independent cell death pathway is apoptosisinducing factor (AIF) which, when released from mitochondria, translocates to the nucleus and induces large-scale DNA fragmentation and cell death. ${ }^{31,32}$ AIF has a dual function in the control of stress-induced cell death, ${ }^{33}$ also being an NADH oxidase, local redox function of which is essential for optimal oxidative phosphorylation and for an efficient anti-oxidant defense. ${ }^{34}$ The adult harlequin $(\mathrm{Hq})$ mouse has about $80 \%$ less brain AIF due to a proviral insertion in the AIF gene. Brain tissue from adult $\mathrm{Hq}$ mice displayed signs of increased oxidative stress, retinal and cerebellar degeneration. ${ }^{34}$ On postnatal day-10 (P10) Hq mice express approximately $60 \%$ less brain AIF than their wild-type (Wt) littermates. ${ }^{32}$ Inhibition

\footnotetext{
${ }^{1}$ Center for Brain Repair and Rehabilitation, Institute of Neuroscience and Physiology, University of Gothenburg, Gothenburg, Sweden; ${ }^{2}$ Department of Obstetrics and Gynecology, Miyazaki Medical College, University of Miyazaki, Kiyotake, Japan; ${ }^{3}$ Maternity \& Perinatal Care Center, Nagoya University Hospital, Nagoya, Japan; ${ }^{4}$ Molecular Neurobiology Group, Biomedical Research Institute, National Institute of Advanced Industrial Science and Technology (AIST), Tsukuba, Ibaraki, Japan; ${ }^{5}$ Department of Pediatrics, Third Affiliated Hospital of Zhengzhou University, Zhengzhou, China; ${ }^{6}$ Department of Obstetrics and Gynecology, Narita Hospital, Nagoya, Japan; ${ }^{7}$ Department of Radiation Physics, Sahlgrenska University Hospital, Gothenburg, Sweden; ${ }^{8}$ Institut National de la Santé et de la Recherche Médicale, U848, Villejuif, France; ${ }^{9}$ Institute Gustave Roussy, Villejuif, France; ${ }^{10}$ Université Paris Sud/Paris 11, Villejuif, France and ${ }^{11}$ Department of Pediatric Oncology, Queen Silvia Children's Hospital, Gothenburg, Sweden

${ }^{*}$ Corresponding author: K Blomgren, Center for Brain Repair and Rehabilitation, Institute of Neuroscience and Physiology, University of Gothenburg, Box 432, 40530 Gothenburg, Sweden. Tel: + 4631786 3376; Fax: + 4631786 3401; E-mail: klas.blomgren@neuro.gu.se

${ }^{12}$ These authors contributed equally to this work.

Keywords: proliferation; stem cell; neurogenesis; progenitor; radiotherapy

Abbreviations: AIF, apoptosis-inducing factor; CypA, cyclophilin A; IR, irradiation; Hq, Harlequin; NPC, neural precursor cell (collective term for stem and progenitor cells); SVZ, subventricular zone; TUNEL, TdT-mediated dUTP nick end labeling; Wt, wild type.

Received 26.5.10; revised 09.7.10; accepted 15.7.10; Edited by G Melino
} 
or depletion of AIF can provide neuroprotection in vitro and in vivo. ${ }^{32,35-37}$ Administration of AIF-neutralizing antibodies can reduce NMDA excitotoxicity, ${ }^{35}$ and knockdown of AIF with small interfering RNA (siRNA) protects primary cultures of hippocampal neurons from glutamate toxicity ${ }^{36}$ and primary cortical neurons from stretch-induced injury. ${ }^{38}$ Adult Hq mice displayed approximately $40 \%$ smaller infarcts in a model of focal ischemia ${ }^{36}$ and $44 \%$ less secondary contusion expansion after traumatic brain injury. ${ }^{38}$ Similarly, neonatal $\mathrm{Hq}$ mice displayed approximately $50 \%$ smaller infarcts after hypoxia-ischemia. ${ }^{32}$

Recently, we demonstrated that in a model of IR-induced progenitor cell death, X-linked inhibitor of apoptosis-protein overexpression failed to mitigate cell death in the neurogenic regions, even though it decreased caspase activation ${ }^{15}$ and oxidative stress, ${ }^{39}$ presumably because there was a concurrent compensatory increase in the nuclear translocation of AIF. ${ }^{15}$ Inspired by these results, we examined whether the reduction of AIF expression could influence IR-induced injury in the young, still developing brain.

\section{Results}

Impact of the $\mathrm{Hq}$ mutation on acute cellular injury after IR. Postnatal day-10 (P10) mice were subjected to IR of the left hemisphere using a single dose of $8 \mathrm{~Gy}$, and we examined the cellular injury $6 \mathrm{~h}$ after IR using the oxidative stress marker 4-hydroxy-2-nonenal (4HNE) and apoptosisrelated markers (AIF, active caspase-3 and TUNEL). Representative photomicrographs of the SVZ in Wt and $\mathrm{Hq}$ mice are shown in Figure 1a-d. Numerous cells displaying nuclear AIF translocation were detected in the SVZ of $\mathrm{Wt}$ mice after IR, not only in the ipsilateral but also in the contralateral hemisphere, but there were very few cells with AIF-positive nuclei in $\mathrm{Hq}$ mice (Figure 1a and e; $P<0.001$ ). The contralateral hemisphere receives a lower dose of scattered, secondary radiation. For example, if the SVZ is irradiated with a direct dose of $12 \mathrm{~Gy}$, the contralateral hemisphere exhibits an injury similar to that observed after direct irradiation with a dose of $4 \mathrm{~Gy}$ (Fukuda et al., ${ }^{15}$ Figure 5). Active caspase-3-positive cells were seen in the SVZ of Wt and Hq mice, but fewer in the contralateral SVZ of Hq mice (Figure $1 \mathrm{~b}$ and $\mathrm{f} ; P<0.01$ ). The density of TUNELpositive cells followed that of active caspase-3-positive cells, that is, many positive cells were seen in the SVZ after $\mathrm{IR}$, and the density in the contralateral SVZ from Hq mice was significantly lower than in Wt mice (Figure $1 \mathrm{c}$ and $\mathrm{g}, P<0.05)$. As expected from the anti-oxidant role of AIF, several-fold more 4HNE-positive cells were seen in the ipsilateral SVZ from $\mathrm{Hq}$ mice (Figure $1 \mathrm{~d}$ and $\mathrm{h} ; P<0.001$ ).

Impact of cyclophilin A deficiency on acute cellular injury after IR. Earlier studies in vitro ${ }^{40}$ and in vivo ${ }^{41}$ indicate that AIF must interact with cyclophilin A (CypA) to execute cell death. We irradiated $\mathrm{Wt}$ and $C y p A^{-1-}$ mice on $\mathrm{P} 10$, and counted the number of cells immunopositive for nuclear AIF or active caspase-3 $6 \mathrm{~h}$ after IR. Very few AIF-positive nuclei were seen in the SVZ of $C y p A^{-/}$mice, compared with $\mathrm{Wt}$ mice (Figure $2 \mathrm{a}$ and $\mathrm{c}$, ipsilateral
$P<0.001$; contralateral $P<0.01$ ). The numbers of active caspase-3-positive cells in the SVZ of $C y p A^{-1-}$ mice were also much lower than those of $\mathrm{Wt}$ mice (Figure $2 \mathrm{~b}$ and $\mathrm{d}$; $P<0.001)$.

Impact of the Hq mutation on SVZ injury after IR. In previous studies, we demonstrated that SVZ size was decreased by IR. ${ }^{14,15,42}$ We irradiated $\mathrm{Wt}$ and $\mathrm{Hq}$ mice on P10 and measured SVZ areas 7 days later. The SVZ area in control, non-irradiated $\mathrm{Hq}$ and heterozygous (Het) mice was approximately half the size of that in non-IR Wt mice (Figure 3). The SVZ area was reduced by IR in Wt mice (44 and $55 \%$ in the contra- $(P<0.05)$ and ipsilateral hemispheres $(P<0.01)$, respectively (Figure $3 e)$. In contrast, neither $\mathrm{Hq}$ nor Het mice displayed any reduction in SVZ areas after IR (Figure 3e).

Vulnerability of stem cells versus committed progenitors in the SVZ of Hq mice after IR. To examine the effects of IR on non-committed stem cells versus committed neural progenitor cells, we irradiated $\mathrm{Wt}$ and $\mathrm{Hq}$ mice on P10. At7 days after IR, we counted the number of cells positive for the transcription factor PAX6 (a marker of immature cells in neurogenic regions) and doublecortin (DCX, a marker of neuronal progenitors) (Figure 4a). The number of PAX6-positive cells was reduced after IR in the ipsilateral SVZ of Wt $(P<0.01)$ but not Hq mice (Figure $4 \mathrm{~b})$. We also counted the number of cells double-positive for PAX6 and DCX (PAX6+/DCX + , indicating neuronally committed cells) and PAX6-positive, DCX-negative cells (PAX6 $+/ D C X-$, indicating non-committed or glialcommitted cells). Approximately half of the PAX6-positive cells were DCX-negative (Figure $4 b-d$ ), and these cells were generally located closer to the ventricular surface (Figure 4a), as expected. The density of PAX6 $+/ D C X+$ cells tended to be reduced by IR in the ipsilateral SVZ of Wt mice, although not significantly so (Figure 4c; $P=0.067$ ). In contrast, IR significantly reduced the density of PAX6 + I DCX - cells, both in the contralateral $(P<0.05)$ and in the ipsilateral SVZ of Wt mice $(P<0.01)$, suggesting that they are more radiosensitive than $\mathrm{PAX} 6+/ \mathrm{DCX}+$ cells in $\mathrm{Wt}$ mice. The density of PAX $6+/ D C X-$ cells was lower in control, non-IR Hq mice than in non-IR Wt mice $(P<0.01)$, but unlike in Wt mice, the number was not affected by IR in the $\mathrm{Hq}$ mice (Figure $4 \mathrm{~d}$ ).

Impact of the Hq mutation on cultured neural precursor cells after IR. We examined the effects of the $\mathrm{Hq}$ mutation on cultured neural stem and progenitor cells, here collectively called neural precursor cells (NPCs), from the SVZ after IR. We irradiated NPCs using a single dose of 2 or $4 \mathrm{~Gy}$. At $4 \mathrm{~h}$ after IR, we counted the number of living (Trypan blue-excluding) cells and evaluated their viability, as judged by the conversion of the tetrazolium salt WST-1, requiring a functional mitochondrial respiratory chain. The number of living NPCs after 2 Gy was $45 \%$ higher in the $\mathrm{Hq}$ than in the Wt cultures (Figure 5a; $P<0.05$ ). The WST-1 assay demonstrated that the viability of NPCs from the SVZ of Hq mice $4 \mathrm{~h}$ after IR was significantly higher than the viability 
a

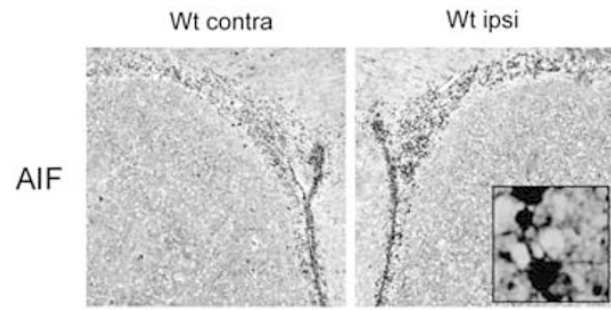

b

Casp-3

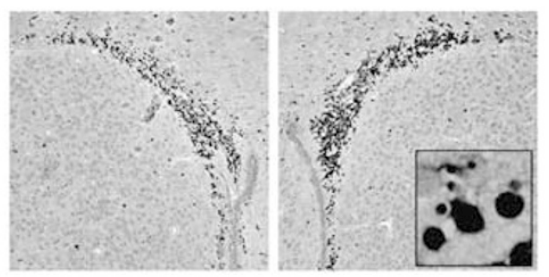

C

TUNEL

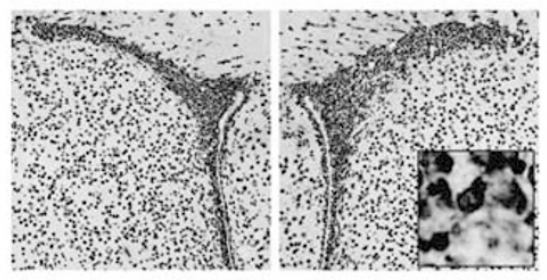

d

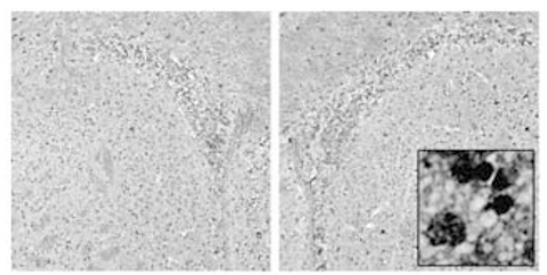

e
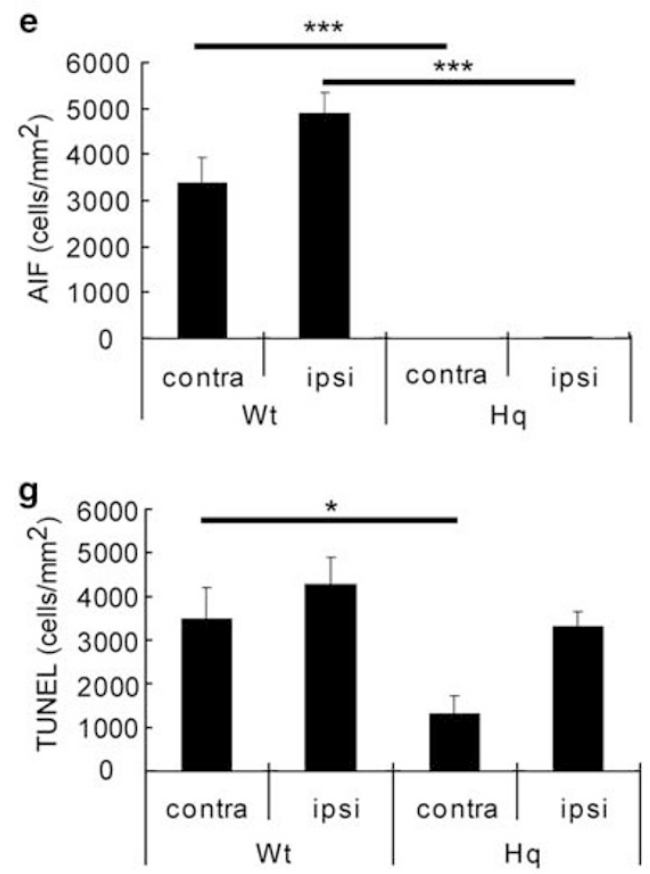

$\mathrm{Hq}$ contra
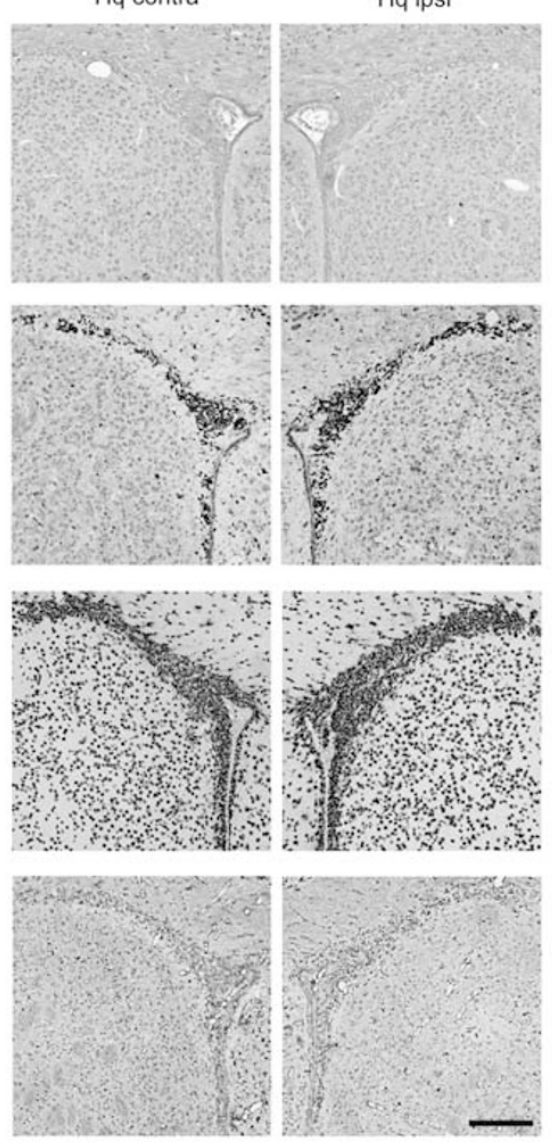

f

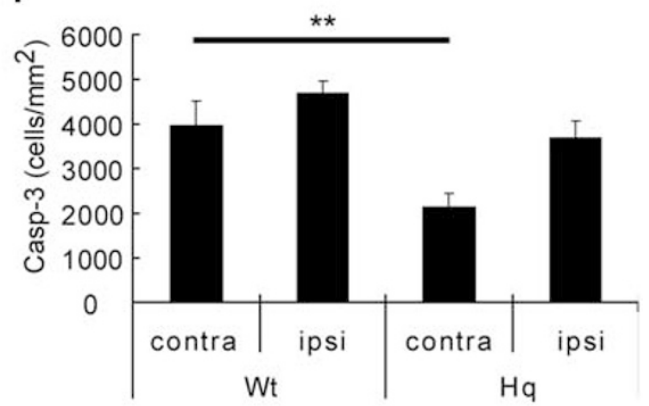

h

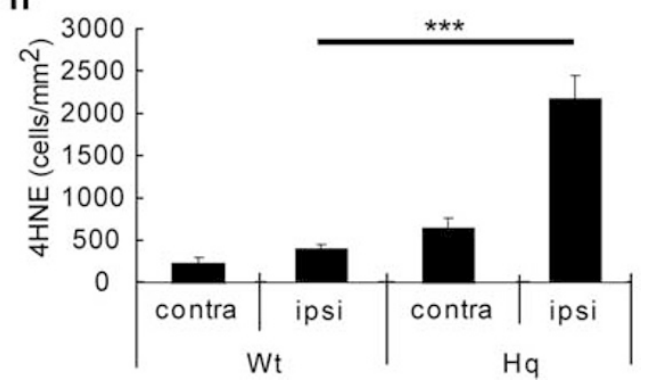

Figure 1 Impact of the Hq mutation on acute cellular injury after IR. Representative microphotographs of the SVZ stained for AIF (a), active caspase-3 (b), TUNEL (c) or the oxidative stress marker 4HNE (d) in Wt and Hq mice in the contra- and ipsilateral hemisphere $6 \mathrm{~h}$ after IR. Bar $=200 \mu \mathrm{m}$. Quantification of AIF- (e), active caspase-3- (f) TUNEL- $(\mathbf{g})$ and 4HNE-positive $(\mathbf{h})$ cells in the SVZ $6 \mathrm{~h}$ after IR is shown for Wt and Hq mice in the contra- and ipsilateral hemisphere. Data represent mean \pm S.E.M. ${ }^{*} P<0.05,{ }^{* *} P<0.01$ and ${ }^{* \star *} P<0.001, n=6$ or 7 per group 
a

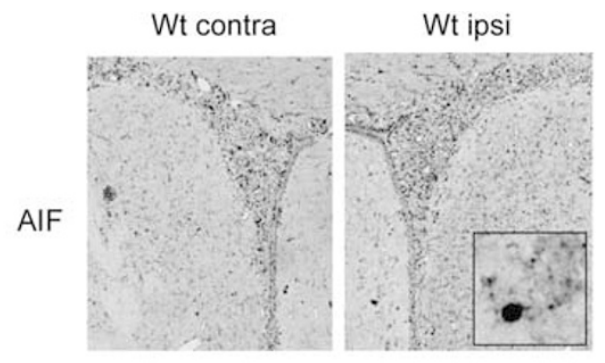

b

Casp-3

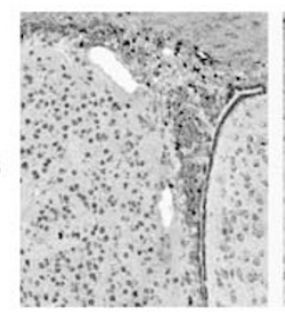

c

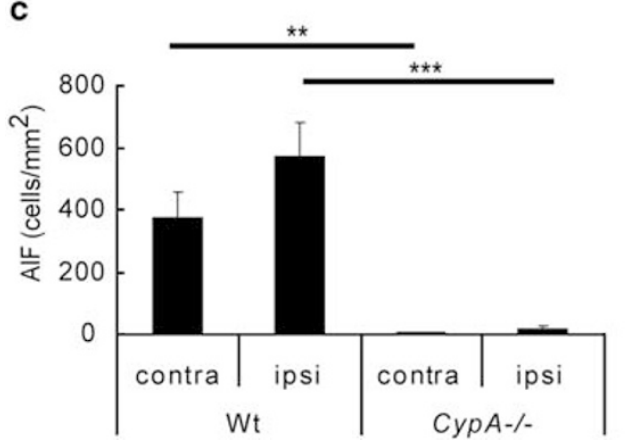

d
CypA-/- contra

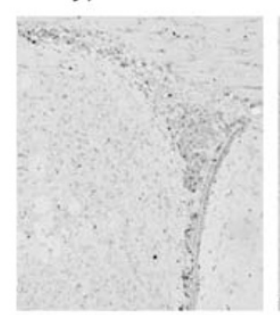

CурA- - ipsi
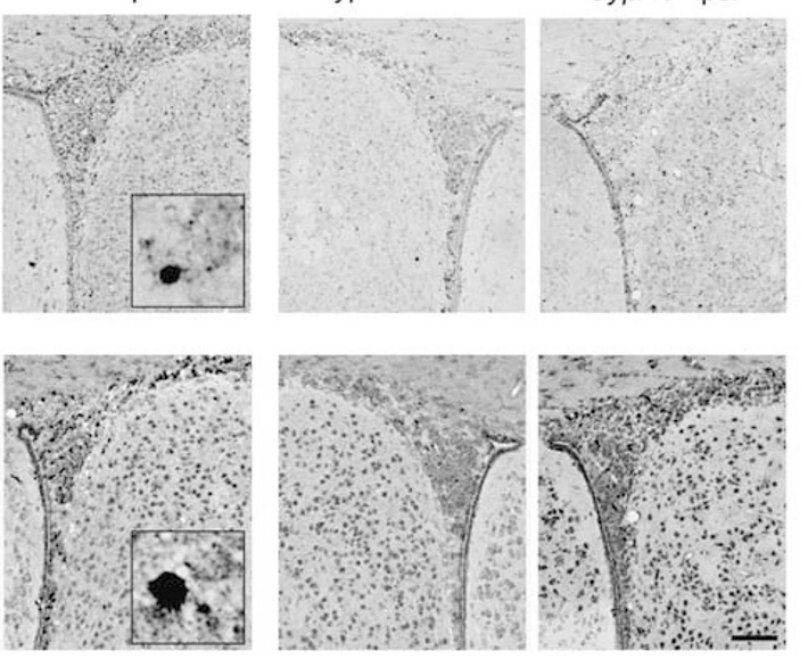

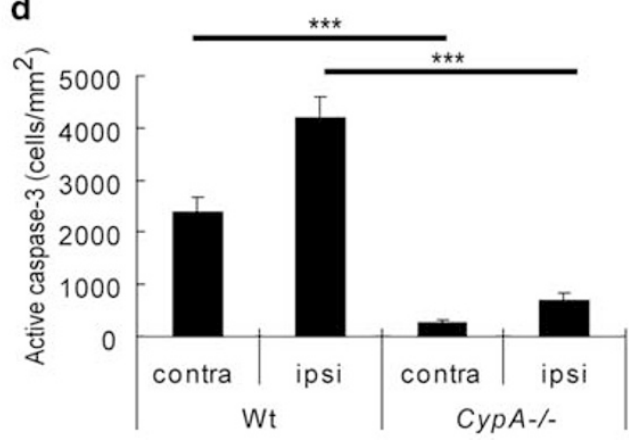

Figure 2 Impact of cyclophilin A deficiency on acute cellular injury after IR. Representative microphotographs of the SVZ stained for AIF (a) and active caspase-3 (b). $\mathrm{Bar}=100 \mu \mathrm{m}$. The number of AIF- (c) and active caspase-3-positive (d) cells in the SVZ $6 \mathrm{~h}$ after IR is shown for Wt and CypA ${ }^{-/-}$mice. Data represent mean \pm S.E.M. ${ }^{* *} P<0.01$ and ${ }^{* * *} P<0.001, n=10$ per group

of NPCs from Wt mice (Figure $5 \mathrm{~b} ; P<0.05$, after both 2 and 4 Gy).

Cell proliferation in the SVZ of non-irradiated $\mathrm{Hq}$ mice. We examined the proliferation rate of precursor cells in the SVZ of $\mathrm{Wt}$, Het and $\mathrm{Hq}$ mice through BrdU pulse labeling. The number of BrdU-labeled cells was counted $24 \mathrm{~h}$ after injection. Representative stainings from the SVZ of Wt and $\mathrm{Hq}$ mice are shown in Figures $6 \mathrm{a}$ and $\mathrm{b}$, respectively. The density of labeled cells was significantly lower in $\mathrm{Hq}$ and Het mice than in Wt mice (Figure 6c; Wt versus Het $20 \%$, $P<0.05$; Wt versus $\mathrm{Hq} 33 \%, P<0.001)$. We also evaluated the viability of non-irradiated SVZ NPCs in vitro using the WST-1 assay and found that the signal was $15 \%$ lower in $\mathrm{Hq}$ NPCs after 4 days in culture (Figure $6 \mathrm{~d} ; P<0.05$ ). Provided that cell size and survival rates are the same in $\mathrm{Wt}$ and $\mathrm{Hq}$ NPCs, this indicates that the proliferation rate was lower in Hq NPCs.

\section{Impact of free radical scavenging on the SVZ in Hq mice} after IR. AIF deficiency renders cells more sensitive to oxidative stress, as shown above by higher numbers of 4HNE-positive cells after IR in $\mathrm{Hq}$ versus $\mathrm{Wt}$ mice. We hypothesized that increased susceptibility to oxidative stress after IR would counteract the protective effects of AIF deficiency. To investigate this, we treated mice with the free radical scavenger edaravone, using a dose that was effective in $\mathrm{Hq}$ mice subjected to hypoxia-ischemia. ${ }^{32} \mathrm{We}$ irradiated mice on P10 and injected edaravone twice, immediately before and immediately after IR. There was no significant difference between the edaravone- and vehicletreated mice 7 days after IR in any genotype, neither in the ipsilateral nor in the contralateral hemispheres, with respect to their SVZ areas (Table 1).

\section{Discussion}

AIF deficiency protects against IR in the SVZ through a blunted apoptotic response. Together, these findings in vivo and in vitro indicate that AIF deficiency generates cell-intrinsic properties that make neural precursor cells more resistant to ionizing radiation. It is possible that cell-extrinsic properties of the SVZ neurogenic niche also provide protective factors. ${ }^{43}$ We have shown earlier that CypA is necessary for injury-induced AIF translocation to nuclei in vitro ${ }^{40}$ and after cerebral ischemia in vivo. ${ }^{41}$ Here we show that in the absence of CypA, hardly any AIF-positive nuclei could be observed in the SVZ after IR. Furthermore, hardly any cells positive for active caspase- 3 could be 
non-IR

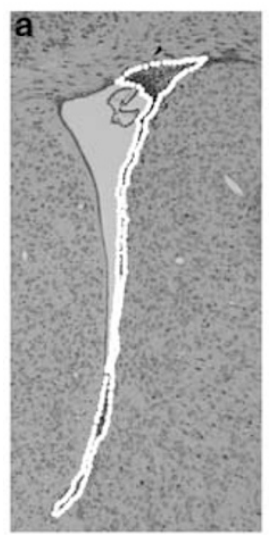

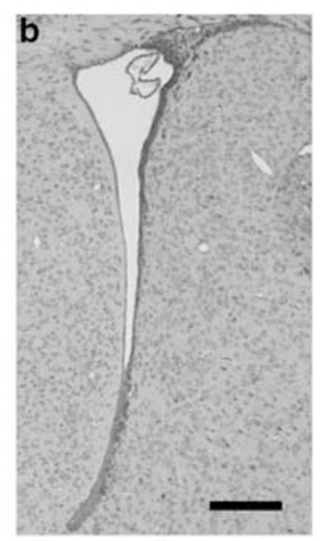

IR
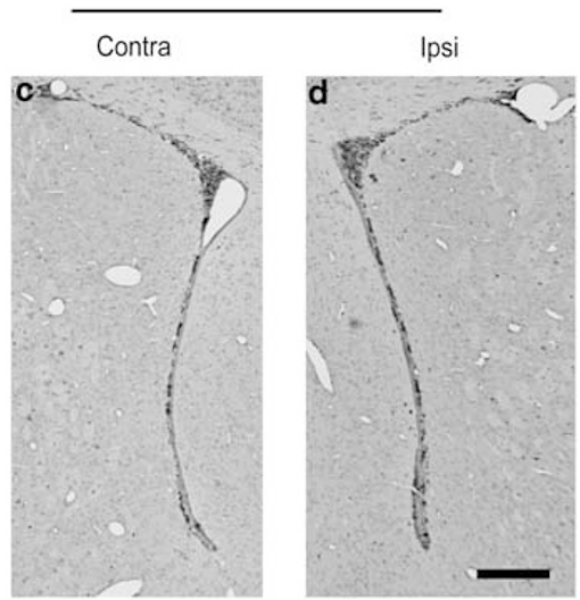

e

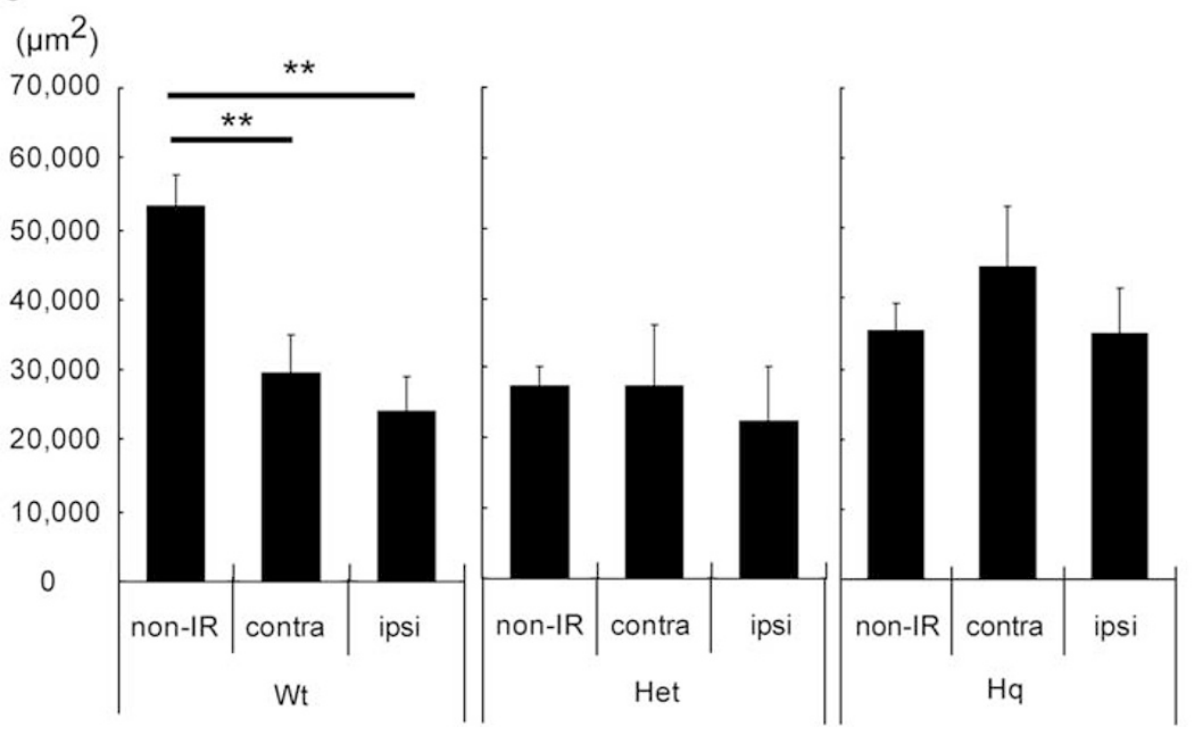

Figure 3 Impact of the Hq mutation on SVZ injury after IR. Representative microphotographs of the SVZ in Wt mice stained with thionin/acid fuchsin 7 days after IR (a-d). We traced the SVZ and evaluated the areas (a, white dotted line) in three equally spaced sections per brain and used the average area as $n=1$. Bar $=100 \mu \mathrm{m}$. Quantification of the SVZ areas of Wt, Het and Hq mice 7 days after IR (e). Data represent mean \pm S.E.M. ${ }^{* *} P<0.01$. Wt: non-IR $n=7$, IR $n=9$. Het: non-IR $n=5$, IR, $n=4$. Hq: non-IR $n=10$, IR $n=9$

detected, indicating that caspase-3 activation, too, was reduced in stem and progenitor cells after $I R$, both in $\mathrm{CypA}^{-/-}$and $\mathrm{Hq}$ mice. This finding is different from cortical tissue after hypoxia-ischemia, where tissue protection was accompanied by abolished AIF translocation to neuronal nuclei, but caspase-3 activation was unaffected. ${ }^{32}$ Irradiation of AIF-deficient Hq mice and CypA-deficient mice helped us confirm that AIF is important not only in brain injury after ischemia and trauma, but also in IR-induced precursor cell death in the SVZ. The size of the SVZ reflects the number of proliferating cells, making SVZ size a useful surrogate marker in this respect. ${ }^{44}$ Finding lower densities of injured cells in $\mathrm{Hq}$ brains even underestimates the effect of AIF deficiency, as an identical number of injured cells in a smaller area would yield an increased density.
AIF deficiency protects against IR in the SVZ through decreased proliferation. The biological basis for cranial radiotherapy is, partly, that malignant tumor cells proliferate rapidly and hence are more susceptible to the extensive DNA damage and oxidative stress induced by ionizing radiation. Astrocytes and postmitotic neurons in the brain are relatively radioresistant, but the neurogenic regions, where extensive cell proliferation occurs throughout life, particularly in the young brain, are highly sensitive to IR. Hence, a decreased proliferation rate would likely confer relative protection against IR. We observed that the SVZ size was smaller in Het and $\mathrm{Hq}$ mice, and that this could be attributed, at least partly, to a lower number of non-committed or glial-committed (PAX6+/DCX-) stem and progenitor cells. Interestingly, the numbers of neuronal-committed 
a
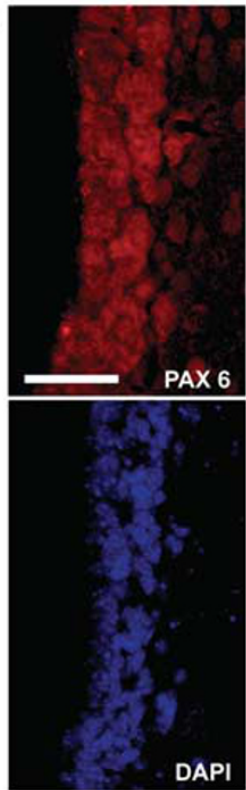

C

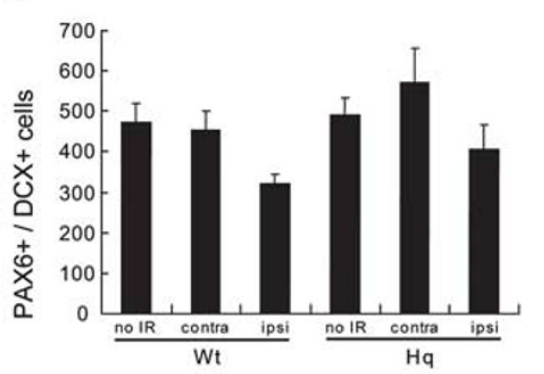

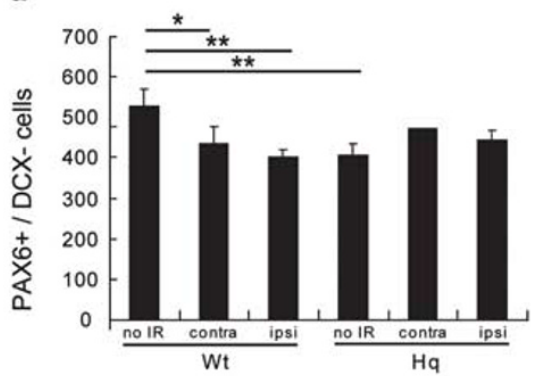

Figure 4 Stem/progenitor cells in the SVZ of Hq mice after IR. Representative microphotographs of the SVZ (a) stained for PAX6 (red) and doublecortin (DCX) (green) 7 days after IR. Bar $=25 \mu \mathrm{m}$. Quantification of the number of (b) the PAX6-positive cells, (c) the PAX6- and DCX-positive cells (PAX6 +/DCX + ) and (d) the PAX6-positive, DCX-negative cells (PAX6 + /DCX-). Data represent mean \pm S.E.M. ${ }^{*} P<0.05,{ }^{* \star} P<0.01, n=7$ per group
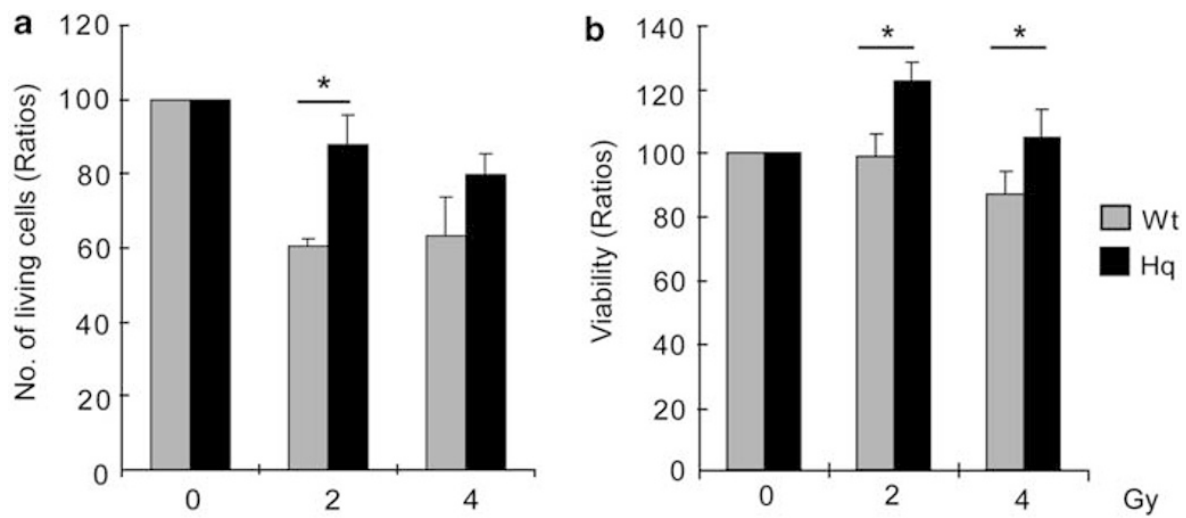

Figure 5 Impact of the Hq mutation on cultured neural percursor cells after IR. (a) The number of living NPSCs from the SVZ of Wt and Hq mice $4 \mathrm{~h}$ after 2 or $4 \mathrm{~Gy}$ IR ( $n=4$ per group). (b) The viability of NPSCs from the SVZ of Wt and Hq mice $4 \mathrm{~h}$ after 2 or $4 \mathrm{~Gy} \mathrm{IR.} \mathrm{(} n=10$ per group). Counting and evaluation of viability were performed as described in Materials and methods, and data represent mean \pm S.E.M. ${ }^{*} P<0.05$

progenitors (PAX6 $+/ \mathrm{DCX}+$ ) were not different between the genotypes. BrdU pulsing revealed a dose-dependent decrease in the proliferation rate in the SVZ of Het and $\mathrm{Hq}$ mice, such that $\mathrm{Hq}$ mice displayed fewer BrdU-labeled cells in the SVZ than Wt mice. This decreased proliferation rate was confirmed in vitro, where NPCs isolated from the SVZ of $\mathrm{Hq}$ mice were demonstrated to proliferate at a slower rate than cells from $\mathrm{Wt}$ mice, indicating that the reduced 

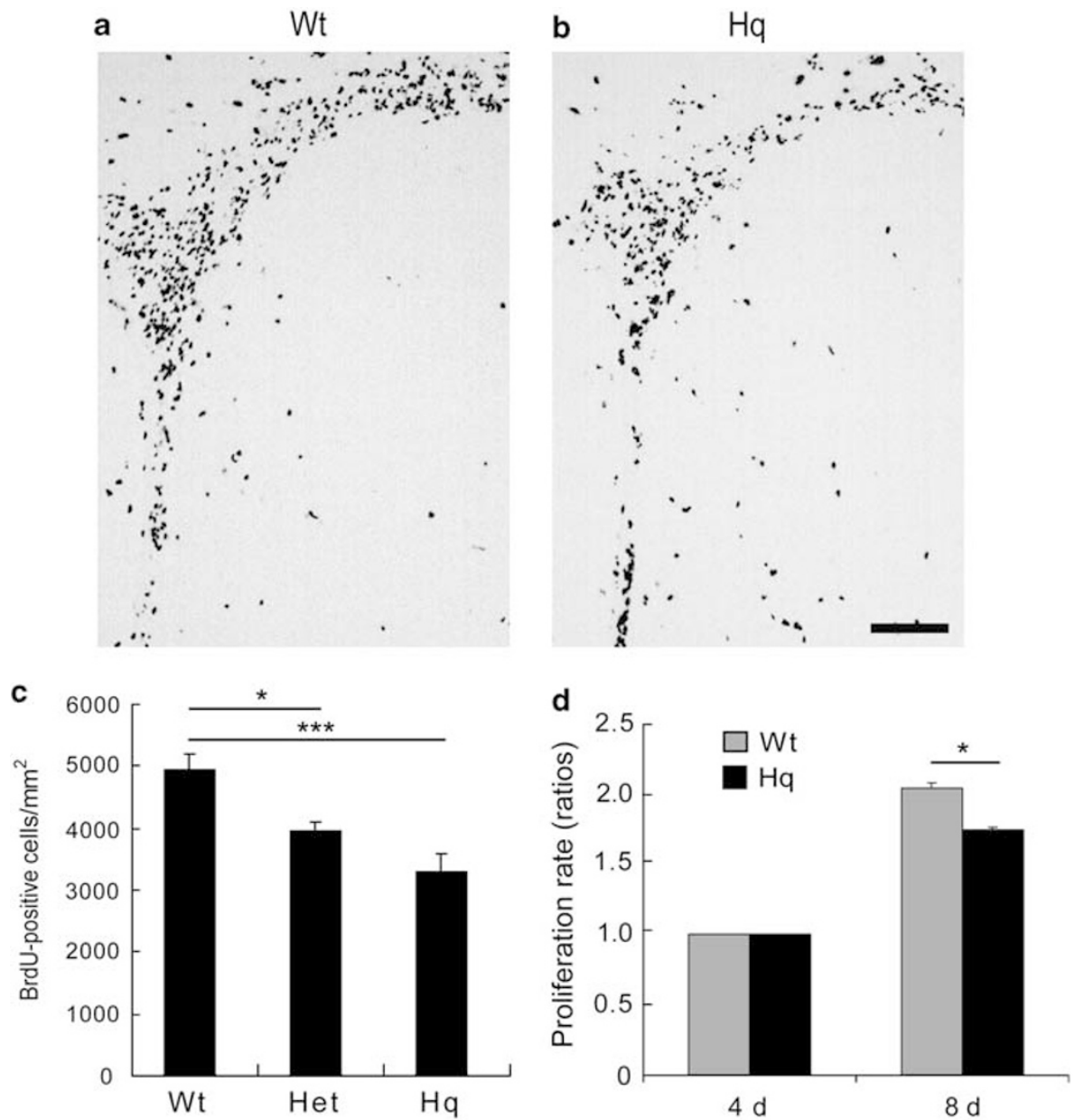

Figure 6 Cell proliferation in the SVZ of non-IR Hq mice. Representative microphotographs from Wt (a) and $\mathrm{Hq}(\mathbf{b})$ brains of the SVZ stained for BrdU $24 \mathrm{~h}$ after injection on P10, without IR. Bar $=100 \mu \mathrm{m}$. (c) Quantification of the BrdU-positive cells in the SVZ of Wt $(n=6)$, Het $(n=6)$ and $\mathrm{Hq}(n=7)$. (d) Proliferation of cultured NSPCs from the SVZ of Wt and Hq mice 4 and 8 days after plating ( $n=10$ per group). Data represent mean \pm S.E.M. ${ }^{*} P<0.05,{ }^{* \star \star} P<0.001$

Table 1 Impact of free radical scavenging

\begin{tabular}{|c|c|c|c|c|c|c|}
\hline \multirow[b]{2}{*}{ Treatment } & \multicolumn{2}{|c|}{$\mathrm{Wt}\left(\mu \mathrm{m}^{2}\right)$} & \multicolumn{2}{|c|}{ Het $\left(\mu \mathrm{m}^{2}\right)$} & \multicolumn{2}{|c|}{$\mathrm{Hq}\left(\mu \mathrm{m}^{2}\right)$} \\
\hline & Contralateral & Ipsilateral & Contralateral & Ipsilateral & Contralateral & Ipsilateral \\
\hline $\begin{array}{l}\text { Vehicle } \\
\text { Edaravone }\end{array}$ & $\begin{array}{l}48.2 \pm 4.0 \\
49.1 \pm 2.7\end{array}$ & $\begin{array}{l}39.4 \pm 2.3 \\
36.6 \pm 1.5\end{array}$ & $\begin{array}{l}38.9 \pm 2.5 \\
47.8 \pm 2.8\end{array}$ & $\begin{array}{l}31.5 \pm 1.4 \\
34.7 \pm 2.9\end{array}$ & $\begin{array}{l}44.0 \pm 1.6 \\
45.8 \pm 2.4\end{array}$ & $\begin{array}{l}37.5 \pm 2.5 \\
38.0 \pm 2.6\end{array}$ \\
\hline
\end{tabular}

The SVZ areas in Wt, Het and Hq mice were measured in the contra- and ipsilateral hemispheres 7 days after IR. There were no significant differences between the groups. Vehicle: Wt, Het, Hq, $n=7,5$ and 5 per group, respectively; edaravone: $n=6$ per group. Data represent mean \pm S.E.M.

proliferation rate is caused by cell-intrinsic factors rather than differences in the niche. The biological basis for the altered rate of proliferation remains to be investigated. We recently showed that the SVZ and the dentate gyrus respond differently to $I R^{43}$ and it remains to be elucidated to what extent AIF is involved in these differences.

Oxidative stress after IR. Irradiated neural precursor cells in culture were reported to exhibit an acute, dose-dependent apoptosis accompanied by an increase in reactive oxygen species (ROS) that persisted over a 3-4-week period. ${ }^{45}$
It has also been demonstrated in vivo that IR induces oxidative stress in the neurogenic regions. ${ }^{15,17,32,39,45}$ Oxidative stress can affect proliferation and neurogenesis, and subsequently also cognitive function. ${ }^{45}$ Recently, it has been shown that the essential fatty acid precursor eicosapentaenoic acid reduced ROS levels and resulted in less radiation-induced injury in the adult rat brain. ${ }^{17} \mathrm{Hq}$ mice are more susceptible to oxidative stress, ${ }^{32,34}$ but the free radical scavenger edaravone did not provide any beneficial effects, as judged by the SVZ size reduction 7 days after IR. This stands in contrast to a study showing in vivo 
radioprotection by edaravone after whole-body irradiation of mice $^{46}$ and an in vitro study showing that edaravone could restore the differentiation of human neural precursor cells after radiation-induced oxidative stress. ${ }^{47}$ It is possible that this is a matter of dose, or that the DNA damage inflicted by IR overrides the blunted oxidative stress in the SVZ.

In summary, we have demonstrated that AIF deficiency protects against IR in the neurogenic SVZ of the young mouse brain. The mechanisms underlying the protection appear to be twofold, a blunted apoptotic response and decreased proliferation rate of stem and progenitor cells in the SVZ. To our knowledge, this is the first report showing that AIF deficiency exerts protective effects against IR, and also the first report indicating that AIF is important for the regulation of proliferation.

\section{Materials and Methods}

Animals. All animal experimental protocols in this study were approved by the Gothenburg animal ethics committee of the Swedish Board of Agriculture (407-2004, 90-2005). Hq mice were from the Jackson Laboratory, Bar Harbor, ME, USA. CypA ${ }^{-1-}$ mice were generated as described ${ }^{48}$ and maintained on a mixed genetic background. ${ }^{41}$ Genotyping for $\mathrm{Hq}$ and $\mathrm{CypA}^{-/-}$mice was performed as previously described ${ }^{32,41}$

Irradiation procedure. For IR of animals, a linear accelerator (Varian Clinac $600 \mathrm{CD}$ ) with $4 \mathrm{MV}$ nominal photon energy and a dose rate of $2.3 \mathrm{~Gy} / \mathrm{min}$ was used. Mice (10-day-old) of both sexes were anesthetized with an intraperitoneal injection of tribromoethanol (Sigma-Aldrich, Stockholm, Sweden) and placed in prone position (head to gantry) on a polystyrene bed. The left cerebral hemisphere was irradiated with a radiation field of $1 \times 2 \mathrm{~cm}$ with no divergence toward the right hemisphere. The source to skin distance was approximately $99.5 \mathrm{~cm}$. The head was covered with a $1 \mathrm{~cm}$ tissue equivalent to achieve an even radiation dose throughout the underlying tissue. A single absorbed dose of $8 \mathrm{~Gy}$ was administered to every mouse. The dose variation within the target volume was estimated to be $\pm 5 \%$. The entire procedure was completed within $10 \mathrm{~min}$. After IR, the pups were returned to their biological dams until killed. Sham control animals were anesthetized but not subjected to IR. Using the LQ-model ${ }^{49}$ and an $\alpha / \beta$-ratio of three for late effects in normal brain tissue, an acute exposure of $8 \mathrm{~Gy}$ is equivalent to approximately $18 \mathrm{~Gy}$ when delivered in repeated $2 \mathrm{~Gy}$ fractions. This dose represents a clinically relevant dose, equivalent to the dose used, for example, in treatment protocols for cranial irradiation in selected cases of childhood acute lymphoblastic leukemia. It is a lower dose than those used for treatment of malignant pediatric brain tumors, which may be as high as $55 \mathrm{~Gy}$.

At 4 days before IR neurospheres were triturated as described below and plated on poly-L-ornithine- (10 $\mu \mathrm{g} / \mathrm{ml}$, Sigma-Aldrich)/Fibronectin- ( $1 \mu \mathrm{g} / \mathrm{ml}$, Sigma-Aldrich) coated 96-well plates or 12-well non-adhesive cell culture plastic plates at 50000 cells/ml. Growing cell cultures were transferred to air-tight culture plastic plates and either sham-irradiated or exposed to a single dose of 2 or $4 \mathrm{~Gy}$, using the same linear accelerator as above, but with a dose rate of $4.5 \mathrm{~Gy} / \mathrm{min}$. After irradiation, cells were returned to incubators until the time of assay. The level of culture medium in the plastic plates was kept at approximately $1 \mathrm{~mm}$. To obtain a uniform radiation dose throughout the culture medium, the plastic plates were positioned inside a polystyrene phantom, $22 \times 22 \times 9 \mathrm{~cm}$. The cells in the plastic plates were approximately $11 \mathrm{~mm}$ from the bottom surface of the phantom. This distance of $11 \mathrm{~mm}$ coincides with the dose maximum (Dmax) of the radiation field. IR was performed from below the phantom, that is, using a gantry angle of $180^{\circ}$, so that the radiation would reach the cell medium before the gaseous space above. The source to cell distance was $91.1 \mathrm{~cm}$. The polystyrene phantom was positioned on a holder without any material between the IR source and the phantom. The dose variation within the culture medium was estimated to be less than $1.5 \%$.

Tissue preparation. Mice were deeply anesthetized $6 \mathrm{~h}$ or 7 days after IR and transcardially perfusion-fixed with $4 \%$ paraformaldehyde in phosphate-buffered saline (PBS). The brains were removed and immersion-fixed in the same solution at $4^{\circ} \mathrm{C}$ for $24 \mathrm{~h}$, dehydrated with a graded series of ethanol and xylene, embedded in paraffin and cut into $5 \mu \mathrm{m}$ coronal sections.
BrdU administration. BrdU (Roche, Mannheim, Germany), $1 \mathrm{mg} / \mathrm{ml}$, dissolved in PBS was injected intraperitoneally once at a dose of $50 \mathrm{mg} / \mathrm{kg}$ on P10 (without IR). Mice were killed $24 \mathrm{~h}$ after the BrdU injection and the brains were prepared as described above.

Histological and immunohistochemical procedures. Sections were stained with thionin/acid fuchsin for morphological analysis, and adjacent sections were immunostained using the following primary antibodies and working concentrations: goat anti-AIF (1:100 in Tris-buffered saline with $0.1 \%$ Tween 20 (TBS-T); sc-9416, Santa Cruz Biotechnology, Santa Cruz, CA, USA), rabbit anti-active caspase-3 (1:50 in PBS; Pharmingen, San Diego, CA, USA), rabbit anti4HNE $(1: 400$ in PBS with $0.1 \%$ Triton X-100; HNE11-S, Alpha Diagnostic International, San Antonio, TX, USA), monoclonal rat anti-BrdU (1:500 in PBS; clone: BU1/75, Oxford Biotechnology Ltd., Oxfordshire, UK). After deparaffinization and rehydration, antigen retrieval was performed by heating the sections for $10 \mathrm{~min}$ in $10 \mathrm{mM}$ citrate buffer (pH 6.0). Nonspecific binding was blocked with $3 \%$ donkey, horse or goat serum (depending on the species used to raise the secondary antibody) in PBS. After blocking, sections were incubated at room temperature for $1 \mathrm{~h}$ with anti-AIF, anti-active caspase-3 or anti-BrdU, or at $4^{\circ} \mathrm{C}$ over night with anti-4HNE primary antibodies, followed by the appropriate biotinylated secondary antibodies for $1 \mathrm{~h}$ (Vector Laboratories, Burlingame, CA, USA). Endogenous peroxidase activity was blocked with $3 \% \mathrm{H}_{2} \mathrm{O}_{2}$ in Tris-buffered saline (TBS) for $10 \mathrm{~min}$, and visualization was performed using an avidin-biotin-peroxidase solution (Vectastain ABC Elite kit, Vector Laboratories) with $0.5 \mathrm{mg} / \mathrm{ml}$ $3,3^{\prime}$-diaminobenzidine enhanced with $15 \mathrm{mg} / \mathrm{ml}$ ammonium nickel sulfate, $2 \mathrm{mg} / \mathrm{ml}$ -D-glucose, $0.4 \mathrm{mg} / \mathrm{ml}$ ammonium chloride and $0.01 \mathrm{mg} / \mathrm{ml}$-glucose oxidase (Sigma-Aldrich).

Immunofluorescence staining. After antigen retrieval, nonspecific binding was blocked for 30 min with $3 \%$ donkey serum in PBS. After blocking, the sections were incubated with mouse anti-PAX6 (1:200 in PBS; MAB 1260, Chemicon International Inc., Temecula, CA, USA) in PBS at $4^{\circ} \mathrm{C}$ over night. After washing with PBS, sections were incubated with donkey anti-mouse 555 (1:400; Invitrogen, Carlsbad, CA, USA) in PBS for $1 \mathrm{~h}$ at room temperature, and were subsequently incubated with goat anti-DCX (1:100 in PBS; sc-8066, Santa Cruz Biotechnology) for $1 \mathrm{~h}$ at room temperature, followed by donkey anti-goat 488 (1:200; Invitrogen) in PBS for $1 \mathrm{~h}$ at room temperature. After washing with PBS, sections were mounted with ProLong Gold antifade reagent with DAPI (Invitrogen).

DNA fragmentation. Detection of DNA strand breaks by TUNEL was performed according to the instructions of the manufacturer (Roche). Following deparaffinization and antigen retrieval, sections were incubated with $3 \%$ bovine serum albumin in $0.1 \mathrm{M}$ Tris- $\mathrm{HCl}(\mathrm{pH} 7.5)$ for $30 \mathrm{~min}$, followed by TUNEL reaction mixture (terminal deoxynucleotidyl transferase, fluorescein-dUTP and deoxynucleotide triphosphate) for $1 \mathrm{~h}$ at $37^{\circ} \mathrm{C}$. Endogenous peroxidase activity was blocked with $0.3 \% \mathrm{H}_{2} \mathrm{O}_{2}$ in methanol for $10 \mathrm{~min}$, followed by $3 \%$ bovine serum albumin in $0.1 \mathrm{M}$ Tris- $\mathrm{HCl}(\mathrm{pH} 7.5)$ for $30 \mathrm{~min}$ at room temperature. Incubation with peroxidase-conjugated anti-fluorescein (diluted $1: 5$ ) at $37^{\circ} \mathrm{C}$ for $30 \mathrm{~min}$ was followed by visualization using $3,3^{\prime}$-diaminobenzidine as described in the previous section.

\section{Neuropathological analysis}

Assessment of injury. Quantitative morphological analysis of the proliferative areas in the irradiated brains was performed on sections stained with thionin/acid fuchsin. The areas of SVZ in the ipsi- and contralateral hemispheres were traced and measured in three sections per animal, 10 sections $(50 \mu \mathrm{m})$ apart, using the software 'Stereo investigator ver. 6' (MBF Bioscience, Williston, VT, USA). The average value obtained for each area was used as $n=1$.

Cell counting. Injured cells (positive for nuclear AIF, active caspase-3, 4HNE or TUNEL $6 \mathrm{~h}$ after IR) were counted throughout the SVZ and expressed as densities. Cells immunopositive PAX6 and/or DCX (7 days after IR) were counted throughout the SVZ and expressed as absolute numbers. All counts and measurements were performed using Stereo investigator ver. 6 (MBF Bioscience, Magdeburg, Germany).

Oxidative stress inhibition. The free radical scavenger edaravone (3-methyl1-phenyl-2-pyrazolin-5-one, MCl-186 from BIOMOL, Plymouth Meeting, PA, USA) was dissolved in $100 \%$ DMSO and diluted 10 times with saline. It was injected twice intraperitoneally at a dose of $10 \mathrm{mg} / \mathrm{kg}(10 \mu / \mathrm{g}$ body weight), immediately before 
and immediately after IR. Control groups received an equivalent volume of saline containing $10 \%$ DMSO.

Preparation of neurosphere cultures. The SVZ was removed from $\mathrm{Hq}$ and Wt mice at the age of P0 to P3. After removal of the meninges, the tissue was minced and digested as described previously. ${ }^{50}$ Cells were cultured as neurospheres in serum-free DMEA/F12 medium $(1: 1$, Invitrogen) or in Neurobasal A medium (Invitrogen) supplemented with B27 (1:50, Invitrogen), GlutaMAX (2 mM, Invitrogen) and penicillin/streptomycin (100 U penicillin, $100 \mu \mathrm{g}$ streptomycin, Invitrogen) at $100000 \mathrm{cells} / \mathrm{ml}$ in non-adhesive cell culture plastic flasks. The medium was supplemented with EGF $(20 \mathrm{ng} / \mathrm{ml}$, Sigma-Aldrich, St. Louis, MO), bFGF (10 ng/ml, Roche) and heparin ( $2 \mu \mathrm{g} / \mathrm{ml}$, Sigma-Aldrich) every other day. For passaging, cells were collected by centrifugation $(500 \times g, 5 \mathrm{~min})$ and the pellet resuspended in $500 \mu \mathrm{l}$ TrypLE Express (Invitrogen) and incubated at $37^{\circ} \mathrm{C}$ for $2 \times 3 \mathrm{~min}$ with gentle trituration between incubations. After the second incubation step, neurospheres were triturated first with a $1000 \mu$ l pipette followed by a $100 \mu$ l pipette, suspended in fresh media and centrifuged as above. Viable cells were counted using a hemacytometer.

Cell viability assay. Cell viability was measured by counting the living cell numbers as described above and also by means of a tetrazolium-based assay. At $4 \mathrm{~h}$ and 4 days after irradiation, neurospheres cultured in 12-well plates were collected and triturated as described above and the number of living cells was counted after Trypan blue staining. The Premix WST-1 cell assay (Takara-bio, Shiga, Japan) was performed according to the manufacturer's instructions. This assay is based on the cleavage of tetrazolium salts by mitochondrial dehydrogenase in viable cells using a colorimetric assay, and thereby enables us to evaluate both cell viability and, provided that cell size and survival rates are unaltered, proliferation.

Statistics. All data are presented as mean \pm S.E.M. Student's t-test was used when comparing two groups, whereas ANOVA followed by Fisher's post hoc test was used when comparing three of more groups. All statistical analyses were performed using SPSS statistics software (SPSS Inc., Chicago, IL, USA). A P-value of $<0.05$ was considered significant.

\section{Conflict of interest}

The authors declare no conflict of interest.

Acknowledgements. We thank Mrs Rita Grandér for excellent technical assistance. This work was supported by the Swedish Research Council, the Swedish Childhood Cancer Foundation (Barncancerfonden), Swedish governmental grants to scientists working in healthcare (ALF), the Torsten and Ragnar Söderberg Foundation, the King Gustav V Jubilee Clinic Research Foundation (JK-fonden), the Frimurare Barnhus Foundation, the Wilhelm and Martina Lundgren Foundation, the Gothenburg Medical Society and the Swedish Society of Medicine.

1. Gustafsson G, Heyman M, Vernby $\AA$. Childhood cancer incidence and survival in Sweden 1984-2005. Karolinska Institute: Stockholm, 2007.

2. Gatta G, Capocaccia R, Stiller C, Kaatsch P, Berrino F, Terenziani M. Childhood cancer survival trends in Europe: a EUROCARE Working Group study. J Clin Oncol 2005; 23: 3742-3751.

3. Magnani C, Pastore G, Coebergh JW, Viscomi S, Spix C, Steliarova-Foucher E. Trends in survival after childhood cancer in Europe, 1978-1997: report from the Automated Childhood Cancer Information System project (ACCIS). Eur J Cancer 2006; 42: 1981-2005.

4. Levy AS. Brain tumors in children: evaluation and management. Curr Probl Pediatr Adolesc Health Care 2005; 35: 230-245.

5. Anderson NE. Late complications in childhood central nervous system tumour survivors. Current Opinion in Neurology 2003; 16: 677-683.

6. Lannering B, Marky I, Lundberg A, Olsson E. Long-term sequelae after pediatric brain tumors: their effect on disability and quality of life. Medical and Pediatric Oncology 1990; 18: $304-310$

7. Chin HW, Maruyama Y. Age at treatment and long-term performance results in medulloblastoma. Cancer 1984; 53: 1952.

8. Duffner PK, Cohen ME, Thomas PR, Lansky SB. The long-term effects of cranial irradiation on the central nervous system. Cancer 1985; 56(Suppl 7): 1841

9. Li FP, Winston KR, Gimbrere K. Follow-up of children with brain tumors. Cancer 1984; 54: 135.

10. Packer RJ, Meadows AT, Rorke LB, Goldwein JL, D'Angio G. Long-term sequelae of cancer treatment on the central nervous system in childhood. Medical and Pediatric Oncology 1987; 15: 241-253.
11. Hall P, Adami HO, Trichopoulos D, Pedersen NL, Lagiou P, Ekbom A et al. Effect of low doses of ionising radiation in infancy on cognitive function in adulthood: Swedish population based cohort study. Bmj 2004; 328: 19.

12. Duffner PK, Cohen ME, Parker MS. Prospective intellectual testing in children with brain tumors. Ann Neurol 1988; 23: 575-579.

13. Packer RJ, Sutton LN, Atkins TE, Radcliffe J, Bunin GR, D'Angio G et al. A prospective study of cognitive function in children receiving whole-brain radiotherapy and chemotherapy: 2-year results. J Neurosurg 1989; 70: 707-713.

14. Fukuda A, Fukuda H, Swanpalmer J, Hertzman S, Lannering B, Marky I et al. Agedependent sensitivity of the developing brain to irradiation is correlated with the number and vulnerability of progenitor cells. J Neurochem 2005; 92: 569-584.

15. Fukuda H, Fukuda A, Zhu C, Korhonen L, Swanpalmer J, Hertzman S et al. Irradiationinduced progenitor cell death in the developing brain is resistant to erythropoietin treatment and caspase inhibition. Cell Death Differ 2004; 11: 1166-1178.

16. Monje ML, Toda H, Palmer TD. Inflammatory blockade restores adult hippocampal neurogenesis. Science (New York, N.Y) 2003; 302: 1760-1765.

17. Lonergan PE, Martin DS, Horrobin DF, Lynch MA. Neuroprotective effect of eicosapentaenoic acid in hippocampus of rats exposed to gamma-irradiation. J Biol Chem 2002; 277: 20804-20811.

18. Limoli CL, Rola R, Giedzinski E, Mantha S, Huang TT, Fike JR. Cell-density-dependent regulation of neural precursor cell function. Proc Natl Acad Sci USA 2004; 101: 16052-16057.

19. Naylor AS, Bull C, Nilsson MK, Zhu C, Bjork-Eriksson T, Eriksson PS et al. Voluntary running rescues adult hippocampal neurogenesis after irradiation of the young mouse brain. Proc Natl AcadSci USA 2008; 105: 14632-14637.

20. Luskin MB. Restricted proliferation and migration of postnatally generated neurons derived from the forebrain subventricular zone. Neuron 1993; 11: 173-189.

21. Eriksson PS, Perfilieva E, Bjork-Eriksson T, Alborn AM, Nordborg C, Peterson DA et al. Neurogenesis in the adult human hippocampus. Nat Med 1998; 4: 1313-1317.

22. Gould E, Beylin A, Tanapat P, Reeves A, Shors TJ. Learning enhances adult neurogenesis in the hippocampal formation. Nat Neurosci 1999; 2: 260-265

23. Peissner W, Kocher M, Treuer H, Gillardon F. Ionizing radiation-induced apoptosis of proliferating stem cells in the dentate gyrus of the adult rat hippocampus. Brain Res Mol Brain Res 1999; 71: 61-68.

24. Monje ML, Mizumatsu S, Fike JR, Palmer TD. Irradiation induces neural precursor-cell dysfunction. Nat Med 2002; 8: 955-962.

25. Tada E, Parent JM, Lowenstein DH, Fike JR. X-irradiation causes a prolonged reduction in cell proliferation in the dentate gyrus of adult rats. Neuroscience 2000; 99: 33-41.

26. Parent JM, Tada E, Fike JR, Lowenstein DH. Inhibition of dentate granule cell neurogenesis with brain irradiation does not prevent seizure-induced mossy fiber synaptic reorganization in the rat. J Neurosci 1999; 19: 4508-4519.

27. Monje ML, Vogel H, Masek M, Ligon KL, Fisher PG, Palmer TD. Impaired human hippocampal neurogenesis after treatment for central nervous system malignancies. Ann Neurol 2007: 62: 515-520.

28. Galluzzi L, Blomgren K, Kroemer G. Mitochondrial membrane permeabilization in neuronal injury. Nat Rev Neurosci 2009; 10: 481-494.

29. Blomgren K, Leist M, Groc L. Pathological apoptosis in the developing brain. Apoptosis 2007; 12: 993-1010.

30. Kroemer G, Martin SJ. Caspase-independent cell death. Nat Med 2005; 11: 725-730.

31. Susin SA, Lorenzo HK, Zamzami N, Marzo I, Snow BE, Brothers GM et al. Molecular characterization of mitochondrial apoptosis-inducing factor. Nature 1999; 397: 441-446.

32. Zhu C, Wang X, Huang Z, Qiu L, Xu F, Vahsen N et al. Apoptosis-inducing factor is a major contributor to neuronal loss induced by neonatal cerebral hypoxia-ischemia. Cell Death Differ 2007: 14: 775-784.

33. Modjtahedi N, Giordanetto F, Madeo F, Kroemer G. Apoptosis-inducing factor: vital and lethal. Trends Cell Biol 2006; 16: 264-272.

34. Klein JA, Longo-Guess CM, Rossmann MP, Seburn KL, Hurd RE, Frankel WN et al. The harlequin mouse mutation downregulates apoptosis-inducing factor. Nature 2002; 419: 367-374.

35. Wang H, Yu SW, Koh DW, Lew J, Coombs C, Bowers W et al. Apoptosis-inducing factor substitutes for caspase executioners in NMDA-triggered excitotoxic neuronal death. J Neurosci 2004; 24: 10963-10973.

36. Culmsee C, Zhu C, Landshamer S, Becattini B, Wagner E, Pellecchia M et al. Apoptosisinducing factor triggered by poly(ADP-ribose) polymerase and Bid mediates neuronal cell death after oxygen-glucose deprivation and focal cerebral ischemia. J Neurosci 2005; 25: 10262-10272

37. Cheung EC, Melanson-Drapeau L, Cregan SP, Vanderluit JL, Ferguson KL, McIntosh WC et al. Apoptosis-inducing factor is a key factor in neuronal cell death propagated by BAX-dependent and BAX-independent mechanisms. J Neurosci 2005; 25: 1324-1334.

38. Slemmer JE, Zhu C, Landshamer S, Trabold R, Grohm J, Ardeshiri A et al. Causal role of apoptosis-inducing factor for neuronal cell death following traumatic brain injury. $A m \mathrm{~J}$ Pathol 2008; 173: 1795-1805.

39. Zhu C, Xu F, Fukuda A, Wang X, Fukuda $H$, Korhonen $L$ et al. X chromosome-linked inhibitor of apoptosis protein reduces oxidative stress after cerebral irradiation or hypoxiaischemia through up-regulation of mitochondrial antioxidants. Eur J Neurosci 2007; 26: 3402-3410. 
40. Cande C, Vahsen N, Kouranti I, Schmitt E, Daugas E, Spahr C et al. AlF and cyclophilin A cooperate in apoptosis-associated chromatinolysis. Oncogene 2004; 23: 1514-1521.

41. Zhu C, Wang X, Deinum J, Huang Z, Gao J, Modjtahedi N et al. Cyclophilin A participates in the nuclear translocation of apoptosis-inducing factor in neurons after cerebral hypoxiaischemia. J Exp Med 2007; 204: 1741-1748.

42. Fukuda $A$, Fukuda $H$, Jonsson $M$, Swanpalmer J, Hertzman S, Lannering $B$ et al. Progenitor cell injury after irradiation to the developing brain can be modulated by mild hypothermia or hyperthermia. J Neurochem 2005; 94: 1604-1619.

43. Hellström NA, Björk-Eriksson T, Blomgren K, Kuhn HG. Differential recovery of neural stem cells in the subventricular zone and dentate gyrus after ionizing radiation. Stem Cells 2009; 27: 634-641.

44. Parent JM, Vexler ZS, Gong C, Derugin N, Ferriero DM. Rat forebrain neurogenesis and striatal neuron replacement after focal stroke. Ann Neurol 2002; 52: 802-813.

45. Limoli CL, Giedzinski E, Rola R, Otsuka S, Palmer TD, Fike JR. Radiation response of neural precursor cells: linking cellular sensitivity to cell cycle checkpoints, apoptosis and oxidative stress. Radiation Research 2004; 161: 17-27.

46. Anzai K, Furuse M, Yoshida A, Matsuyama A, Moritake T, Tsuboi $\mathrm{K}$ et al. In vivo radioprotection of mice by 3-methyl-1-phenyl-2-pyrazolin-5-one (edaravone; Radicut), a clinical drug. J Radiat Res (Tokyo) 2004; 45: 319-323.
47. Ishii J, Natsume A, Wakabayashi $T$, Takeuchi $\mathrm{H}$, Hasegawa $\mathrm{H}$, Kim SU et al. The free-radical scavenger edaravone restores the differentiation of human neural precursor cells after radiation-induced oxidative stress. Neurosci Lett 2007; 423 225-230.

48. Colgan J, Asmal M, Yu B, Luban J. Cyclophilin A-deficient mice are resistant to immunosuppression by cyclosporine. J Immunol 2005; 174: 6030-6038.

49. Fowler JF. The linear-quadratic formula and progress in fractionated radiotherapy. Br J Radiol 1989; 62: 679-694.

50. Wachs FP, Couillard-Despres S, Engelhardt M, Wilhelm D, Ploetz S, Vroemen M et al. High efficacy of clonal growth and expansion of adult neural stem cells. Lab Invest 2003; 83: 949-962.

c) Cell Death and Disease is an open-access journal published by Nature Publishing Group. This work is licensed under the Creative Commons Attribution-Noncommercial-No Derivative Works 3.0 Unported License. To view a copy of this license, visit http://creativecommons.org/licenses/by-nc-nd/3.0/ 